\title{
Una revisión del debate sobre las mujeres y la teoría moral*
}

\author{
SEYLA BENHABIB \\ New School for Social Research
}

La autora del artículo vuelve sobre el debate abierto en torno a las implicaciones de los conocidos trabajos de Carol Gilligan para la presunta universalidad y pertinencia del llamado "paradigma de Kohlberg” del desarrollo moral. Considera que, desde el punto de vista de la teoría feminista, no deben interpretarse los trabajos empiricos de Gilligan en el sentido de la propuesta de una sética femenina del cuidado" como alternativa a la orientación universalista de la ética normativa de la justicia Una teoría moral «adecuada para la forma de vida de las modernas sociedades complejas" requiere "alguna caracterización universalista de la idea de la impancialidad y del punto de vista éticon. Pero de esta caracterización no se deriva una delimitación del ámbito de lo ético como el ámbito de las cuestiones de jus- ticia por oposición a las «cuestiones evaluativas de la vida buena» que serian consideradas meramente "personales". En opinión de S. Benhabib, Habermas y Kohlberg aconfunden el punto de vista de una ética universalista con una definición estricta del ámbito moral", centrado en la justicia. La autora muestra, además, que bajo tal delimitación subyace un subtexto de género que privilegia la perspectiva del varón adulto, olvidando que todos hemos sido niños/as y las relaciones humanas de dependencia y cuidado son básicas en la adquisición de las competencias éticas de los individuos autónomos. Así pues, uen términos ontogenéticos ni la justicia ni el cuidado poseen primacía algunaw, y ninguno de ambos debe solaparse con el espacio de pertinencia de la moral.

Existe ya una ingente cantidad de trabajos, de carácter realmente interdisciplinar, sobre el debate contemporáneo en torno a las relaciones entre feminismo y teoría moral, debate que se puso en marcha en 1982 con la publicación del libro de Carol Gilligan In A Different Voice. Si reflexionamos sobre los diversos temas y desacuerdos del debate podemos encontrar, además de sus méritos intrínsecos, diversas razones por las cuales la obra de Gilligan se convirtió en foco de una controversia tan intensa y, lo que no es menos interesante, nada acre.

Con el libro In A Different Voice se alcanzo una mayoría de edad de los estudios de la mujer en el terreno de la "ciencia normal", en el sentido kuhniano de la expresión. El trabajo de Gilligan, al igual que lo habían hecho libros anteriores, tales como The Reproduction of Mothering de

* Traducción de Carlos Thiebaut. 
Nancy Chodorow en el campo de la teoría de la socialización, A Feeling for the Organism y Reflections on Gender and Science de Evelyn Fox Keller en los estudios sociales sobre la ciencia, o The Man of Reason de Genevieve Lloyd en la historia de la filosofia, puso de relieve las consecuencias de las llamadas de atención sobre «la cuestión de las mujeres» desde dentro del discurso científico establecido. Cuando las mujeres entran a formar parte del cuadro, ya sea como objetos de la investigación de las ciencias sociales o como investigadoras, se tambalean los paradigmas establecidos. Se cuestionan la definición del ámbito de objetos del paradigma de investigación, así como sus unidades de medida, sus métodos de verificación, la supuesta neutralidad de su terminología teórica o las pretensiones de universalidad de sus modelos y metáforas.

El trabajo que Gilligan realizó en el campo de la teoría del desarrollo moral y cognitivo recapitulaba una experiencia sobre la que ya habían llamado la atención las historiadoras de la mujer en sus propias investigaciones. Joan Kelly Gadol describió tal experiencia en un artículo de 1975 que tituló "The Social Relations of the Sexes. Methodological Implications of Women's History» con las siguientes palabras:

Cuando nos dirigimos a la historia para comprender la situación de las mujeres estamos dando por supuesto que la situación de la mujer es una cuestión socialmente relevante. Pero la historia, tal como la hemos encontrado, no parece confirmar tal conciencia [...] En el momento en que esto se ha hecho - en el momento en que asurnimos que las mujeres forman parte de la humanidad en su sentido más pleno- el período o el conjunto de problemas que estamos analizando asume un carácter o un sentido completamente diferente del normalmente aceptado. De hecho, lo que emerge es una sostenida y relativa pérdida de estatus por parte de las mujeres en los períodos de así llamados cambios progresistas [...] De repente vemos esas épocas con una visión doble nueva en la cual cada ojo ve una imagen diferente.

Si Kelly Gadol habla de una "visión doble», en la que cada ojo percibe imágenes distintas, Gilligan se refiere a una voz diversa. En ambos casos la experiencia es la misma, pues la cuestión de la mujer —el que las mujeres sean objeto de investigación y que sean sujetos que desarrollan esa investigación- altera los paradigmas establecidos. Las mujeres descubren diferencias allí donde antes habían dominado las similitudes, perciben disonancia y contradicción donde reinaba la uniformidad, se dan cuenta del doble sentido de las palabras allí donde se habían dado por supuestos los sentidos de los términos y dejan clara la persistencia de la injusticia, la desigualdad y la regresión en el seno de procesos que antes se consideraban justos, igualitarios y progresistas.

En este artículo me fijaré sólo en dos grandes tipos de problemas de entre el amplio conjunto de cuestiones que ha suscitado el trabajo de Gilli- 
gan tanto dentro como fuera de la teoría feminista. La segunda parte de este artículo se centrará sobre el estatuto metodológico de la categoría de "género" y sobre la cuestión de la "diferencia" en la investigación que desarrolló Gilligan sobre las mujeres y la teoría moral, pero en la primera seguiré explorando las implicaciones que para la filosofía moral universalista tienen las investigaciones de nuestra autora.

\section{Las filosofias morales universalistas y el reto de Gilligan}

No cabe duda que si el trabajo de Carol Gilligan suscitó tan amplia controversia y reconocimiento no fue sólo porque representara una mayoría de edad de los estudios de la mujer en el seno de los paradigmas de la ciencia normal. Era igualmente significativo que el tipo de preguntas que Gilligan le hacía al paradigma de Kohlberg se le elevaban también a las filosofías morales neokantianas desde un número creciente de críticas cada vez más influyentes. Como he analizado en otros lugares, las críticas comunitaristas, neoaristotélicas e incluso neohegelianas al kantismo de autores como Michael Walzer, Michael Sandel, Alasdair MacIntyre y Charles Taylor, así como de la misma Gilligan, cuestionan el formalismo, el cognitivismo y las pretensiones de universalidad de las que se revisten las teorías de corte kantiano. De la misma manera que Gilligan ponía en duda la separación entre forma y contenido en la evaluación del juicio moral, así también MacIntyre argumentaba que de la sola ley moral no cabe deducir ningún principio moral sustantivo. ${ }^{2}$ De igual modo que Gilligan daba cuenta del sentido de confusión de las mujeres que eran sujetos de sus experimentos ante un lenguaje moral que les planteaba hasta los dilemas morales más personales, tales como el aborto, en términos de derechos formales, así también Michael Sandel mantenía que una política que se basase sólo en el modelo procesal y jurídico de las relaciones humanas careceria de cierta solidaridad y de la profundidad que suministra la dimensión de la identidad. ${ }^{3} \mathrm{Y}$ de idéntica forma a cómo Gilligan dudaba de que el modelo de desarrollo del juicio moral presentado por Kohlberg pudiera reclamar para sî la universalidad que decía tener a la vista de las dificultades que tal modelo tenía para dar cuenta de los juicios y del sentido del propio yo que tienen las mujeres, ${ }^{4}$ otros autores como Taylor y Walzer cuestionaban que la forma de los juicios morales referidos a la justicia pudiera aislarse tan claramente del contenido cultural de las concepciones de la vida buena. ${ }^{5}$ Había, pues, una señalada convergencia entre el tipo de crítica feminista de Gilligan ante el universalismo kantiano y las objeciones que formulaban estos otros autores. ${ }^{6}$

Pero ¿qué conclusiones cabe extraer de los hallazgos de Gilligan, hallazgos que, por su parte, se han ido moderando con el tiempo, de cara a las filosofias morales universalistas? ¿Sugieren acaso, o incluso proponen, 
la sustitución de una ética de la justicia por una ética del cuidado? Mi propia posición respecto a un tema tan complejo como éste es que, por lo que conocemos hasta ahora de los resultados de Gilligan, no existen razones suficientes como para rechazar las filosofías morales universalistas. Gilligan no nos ha explicado todavía en qué consistiría «una ética del cuidado», por oposición a una "orientación ética hacia un razonamiento basado en el cuidado», ni nos ha suministrado aún la argumentación filosófica necesaria como para formular una concepción diferente de la de Kohlberg respecto a lo que habría de ser el punto de vista ético o la imparcialidad. Más bien y por el contrario, muchas de sus formulaciones tienden a sugerir que le gustaría complementar la ética de la justicia con una orientación ética hacia el cuidado. ${ }^{7}$ Ambas perspectivas, la de la justicia y la del cuidado, serían, pues, complementarias más que antagónicas. No cabe duda de que es posible también intentar formular una «ética femenina del cuidadon, ${ }^{8}$ pero no sería esa la conclusión que cabe extraer del trabajo de la misma Gilligan. Y, precisamente porque no creo que pueda formularse una teoría moral que sea adecuada para la forma de vida de las modernas sociedades complejas sin alguna caracterización universalista de la idea de la imparcialidad y del punto de vista ético, encuentro más fructífera una interpretación de los trabajos de Gilligan que los entienda no como un rechazo total del universalismo -rechazo para el cual existen pocas pruebas en sus textos- sino, más bien, como una contribución al desarrollo de una comprensión postconvencional de la vida moral que no sea formalista y que sea sensible al contexto. Trataré de concretar mi interpretación tomando pie en un análisis penetrante de Lawrençe Blum a propósito de la relación entre las perspectivas de la justicia y el cuidado.

Este autor, en su reciente artículo "Gilligan and Kohlberg: Implications for Moral Theory", esboza una hipotética respuesta a Carol Gilligan tal como podría suministrarla alguien que defendiera una «concepción imparcialista de la moralidad». Con la noción de imparcialismo se caracterizaría, en este contexto, no sólo la concepción kohlbergiana de lo moral, sino también sla concepción hegemónica de la moralidad en la filosofía moral angloamericana y que forma también el núcleo básico tanto de la perspectiva kantiana como de importantes tendencias del pensamiento utilitarista (y, más general, del pensamiento consecuencialista) $\$ .{ }^{9}$ Blum pasa a sugerimos que la relación entre las moralidades imparcialistas y una moralidad del cuidado podría concebirse de ocho posibles formas diferentes:

1. Según la primera posibilidad, podría negarse que la orientación según el cuidado constituya una posición ética claramente diferenciada de la del imparcialismo. "Actuar atendiendo al cuidado es, de hecho, actuar según principios, quizá complejos pero a pesar de todo plenamente univer- 
salizables, que se generan en último término desde un punto de vista imparcial.. ${ }^{10}$

2. Cabe, en segundo lugar, argumentar que si bien es cierto que el cuidado hacia los demás constituye un conjunto de preocupaciones y de relaciones genuinamente importantes en la vida humana, tales inquietudes pertenecen más al orden personal que al moral. ${ }^{11}$

3. La tercera posición admite que las preocupaciones por el cuidado y la responsabilidad son plenamente morales (y no sólo personales), pero afirmaria que son secundarias con respecto a los principios de imparcialidad, de justicia y de universalidad, así como que son parasitarios de ellos y/o que son menos importantes que ellos. ${ }^{12}$

4. Podría decirse, también, que el cuidado es plenamente moral y que es una orientación moral diferenciada de la imparcialidad, pero que sería una orientación inadecuada ya que no puede universalizarse. Cabe argumentar, así, que una ética del cuidado será finalmente insatisfactoria desde un punto de vista moral ya que no podríamos abarcar a toda la humanidad como objeto de nuestro cuidado y de nuestra compasión, y habríamos de permanecer siempre en una dimensión particularista y personal. De esa manera, una ética del cuidado puede trocarse en una moral convencional de grupo según la cual la esencia de la moralidad sería el bienestar del grupo de referencia. Este grupo de referencia puede ser la familia, la nación o un grupo basado en una afinidad particular, digamos una vanguardia artística o política, grupo al que el individuo le debe una especial obediencia. Una ética del cuidado conduce a una moral de grupo que no es universalizable.

5. De acuerdo con la quinta concepción posible, la diferencia que existe entre una ética del cuidado y otra de la imparcialidad yace en los «objetos de la consideración moral» o en la "especificación del ámbito de lo moral». Mientras el cuidado se refiere a la evaluación de las personas, sus motivaciones y el carácter, la imparcialidad atiende a la evaluación de las acciones, los principios y las reglas de la vida institucional.

6. Cabría pensar, en sexto lugar, que si el cuidado y la responsabilidad son respuestas morales apropiadas en determinadas situaciones, las consideraciones de una justicia imparcial son las que fijan los límites dentro de los cuales el cuidado puede guiar nuestro comportamiento. "Las consideraciones de la imparcialidad vencen sobre aquellas otras que nacen del cuidado; si las primeras entran en conflicto con las segundas, ha de ceder el cuidado, ${ }^{13}$

7. La séptima posición puede considerarse como una elaboración ulterior de la anterior. Según esta posibilidad, si bien es cierto que las consideraciones del cuidado son genuinamente morales, su justificación última "se apoya sobre el hecho de que pueden ser validadas o afirmadas desde una perspectiva imparcial». ${ }^{14}$ 
8. La octava y última posición nos sugiere que en el estadio final y más maduro del desarrollo del razonamiento moral las perspectivas de rla justicia y el cuidado" podrían integrarse para formar un único principio moral. ${ }^{15}$

Empleando este esquema, a) me fijaré con mayor detenimiento en la respuesta de Habermas al cuestionamiento que le suponían los trabajos de Gilligan $\mathrm{y}, b$ ) en segundo lugar, sugeriré de qué manera mi propia comprensión de la ética discursiva, en tanto un modelo conversacional de una mentalidad abierta y amplia, hace posible y aún deseable una respuesta diferente a Gilligan.

a) Jürgen Habermas sugiere en "Conciencia moral y acción comunicativa» que Carol Gilligan, especialmente en el artículo del que es coautora junto a J.M. Murphy, «Moral Development in Late Adolescence and Adulthood: A Critique and Reconstruction of Kohlberg's Theory», no alcanzó a desentrañar el complejo conjunto de problemas que surgen durante la transición desde la adolescencia a la edad adulta, cuando el mundo de vida cotidiano de nuestra comunidad pierde su validez inmediata para el individuo y pasa a ser juzgado desde un punto de vista ético. Escribe Habermas:

Así, la formación de un punto de vista ético va de la mano de una diferenciación en el seno de la esfera de lo práctico: las cuestiones morales, que pueden en principio decidirse racionalmente en términos de criterios de justicia o de la universalidad de los intereses, se diferencian ahora de las cuestiones evaluativas que se configuran bajo la categoría general de cuestiones referentes a la vida buena y que sólo son susceptibles de discusión racional dentro del horizonte de una forma de vida histórica concreta o de un estilo de vida individual. La moral concreta de un mundo de vida habitado con ingenuidad se puede caracterizar por el hecho de que las cuestiones éticas y las evaluativas se configuran en un síndrome indiferenciado, mientras que en un mundo de vida racionalizado las cuestiones éticas se diferencian de los problemas de una vida buena. ${ }^{16}$

¿Puede esta observación aplicarse a la argumentación que aportan Gilligan y Murphy según la cual es necesario formular un "contextualismo postconvencional» que habria de tener en cuenta los dilemas que surgen de aplicar los principios éticos en situaciones de vida complejas? Según Habermas, "Carol Gilligan no alcanza a hacer una distinción adecuada entre el problema cognitivo de la aplicación y el problema motivacional del anclaje de las intuiciones morales ${ }^{17}$ Pues tanto el problema cognitivo de cómo hacer que el juicio moral sea sensible al contexto y el problema motivacional de cómo actuar en situaciones concretas a la luz de principios cuya validez se reconoce de manera hipotética sólo surgen cuando se abstrae el punto de vista ético de las certezas de una forma de vida compartida y cuando esta forma de vida se ha sometido al test hipotético de la imparcialidad. En otras palabras, aunque Gilligan y Murphy pusieron su 
dedo en la llaga de una cuestión importante - la de cómo pueden los sujetos morales que han alcanzado un estadio postconvencional de razonamiento moral comportarse y emitir juicios en situaciones de vida concretas- sus intuiciones se centran sólo sobre la "aplicación» de una moralidad postconvencional y universalista a situaciones de vida. De esa manera, el programa del "contextualismo postconvencional" no tiene relevancia alguna para la justificación o determinación del ámbito de lo moral.

Habermas está, así, de acuerdo con una de las objeciones que Kohlberg le había presentado a Gilligan y según la cual el trabajo de esta última confunde los "temas de la justicia» con los de la "vida buena" haciendo borrosas, de esa forma, las fronteras de lo moral. ${ }^{18}$. "En términos de la conducta de una vida individual, esta diferencia se corresponde con la distinción entre autodeterminación y autorrealización», escribe Habermas. "Con frecuencia, las cuestiones que atañen a las preferencias por formas o ideales de vida (ideales del yo) y también aquellas otras que conciernen a la evaluación de la personalidad y de los modos de acción sólo surgen una vez que se han respondido las preguntas éticas en sentido estricto.» ${ }^{19}$

Lo que Habermas está afirmando con esta respuesta es que el tipo de problemas que Gilligan pone de relieve pertenecen a la periferia de la teoría moral y que son "anomalias» o problemas subsidiarios de un paradigma científico que es, por lo demás, adecuado. Empleando el esquema de Lawrence Blum podemos decir que para Habermas las relaciones entre la justicia y el cuidado se encuadran en las posiciones 1 y 2 . Es decir, los temas referentes al cuidado de los otros y a la responsabilidad hacia ellos que nacen del entrainado de relaciones especiales que con ellos mantenemos son "cuestiones evaluativas referidas a la vida buena», se refieren, por lo tanto, a formas o a metas de vida y a la kevaluación de tipos de personalidad y de modos de acción». En las sociedades modernas, en las cuales las cuestiones éticas de la justicia se han diferenciado de las cuestiones evaluativas de la vida buena, las relaciones y las obligaciones del cuidado y de la responsabilidad son cuestiones "personales" referidas a la autorrealización. Quizá un ejemplo nos podría ayudar a entender mejor la posición de Habermas dadas las dificultades que pudiera ocasionar el que gran parte de su discusión a propósito de la posición de Gilligan esté expresada en su peculiar terminología.

Partamos del ya generalmente bien aceptado principio según el cual los miembros jóvenes de una familia no están obligados a continuar el negocio familiar o a tener igual profesión que el padre sino que, por el contrario, esos jóvenes deberían desarrollar aquellas carreras y profesiones que más adecuadas fueran a su talento y sus capacidades. Este principio se origina históricamente con el surgimiento de una economía de mercado universalizada y con el sostenido declinar de la familia como unidad económica de producción en el mundo modemo. Mientras que en la mayoría 
de las formaciones económicas precapitalistas, e incluso en algunas formas de capitalismo industrial y mercantil, las diversas generaciones de una misma familia actuaban como una unidad económica -por ejemplo, en la forma de un negocio o de una firma familiar-, con el desarrollo del capitalismo y el periclitar continuado de los sistemas feudales los hijos no siguieron ya los pasos de los padres y dejaron de asumir como propia la vocación o la empresa familiar. Con el tiempo llegó a aceptarse que los niños, especialmente los varones, podían y aun debían seguir aquella vocación que encontraran más acorde con sus capacidades. Así, las expectativas morales que gobernaban la vida familiar en la mayoría de los países occidentales hasta los años veinte o treinta, aproximadamente, se han visto sujetas a procesos de diferenciación. La elección de una carrera por parte de la generación más joven no es ya un tema "moral» dependiente de la obligación hacia los otros miembros de la familia, y en concreto hacia el pater familias, sino una cuestión "evaluativa» referente a la buena vida de esa generación. No obstante, pudiera seguir siendo un problema moral para una familia moderna liberal el si enviar a una universidad privada muy cara al hijo primogénito que está menos dotado intelectualmente, en vez de enviar a la facultad de medicina a la hija menor y más dotada, pues tal decisión incluye un problema de justicia, de intereses en conflicto sobre una base de recursos escasos. Pero ni la decisión del hijo de estudiar ciencias empresariales ni la de la hija de estudiar medicina son cuestiones morales y son sólo cuestiones evaluativas referentes a la vida buena.

A pesar de su claridad, esta conclusión choca radicalmente con nues* tras intuiciones y se encuentra muy alejada de la realidad moral cotidiana. Si el ejemplo que acabo de aportar alcanza a captar correctamente el significado de lo que Habermas quiere decir, habría algo muy extraño en su insistencia en que estos temas son "personales" en tanto opuestos a "morales». De hecho, esa afirmación es tan contraria a nuestras intuiciones morales como lo es la afirmación de Kohlberg, según la cual «los ámbitos del parentesco, del amor, de la amistad y del sexo que suscitan consideraciones referidas al cuidado pueden entenderse normalmente como esferas de toma de decisiones personales, tal como sucede con los problemas del matrimonio y el divorcios. ${ }^{20}$ Pero es obvio que esas cuestiones son tan personales como morales. Incluso en las sociedades modernas y altamente racionalizadas, en las que la mayoría de nosotras somos asalariadas y ciudadanas políticas, los temas morales que más nos preocupan y que más nos conmueven nacen no de los problemas de justicia, ya sean económicos o políticos, sino de aquellos otros que surgen de la calidad de nuestras relaciones con los demás en ulos ámbitos del parentesco, del amor, de la amistad y del sexon. Ciertamente, podemos lamentarnos de la esterilidad de nuestra vida política como ciudadanos y podemos anhelar una vida cívica más atrayente e interesante, como he argumentado en otros lugares; 
podemos también rechazar el hecho de que nuestras instituciones económicas sean tan injustas y tan inmorales como lo son si las contemplamos desde el punto de vista de la satisfacción de las necesidades básicas de millones de habitantes de la Tierra, pero nada de ello aminora el que los temas morales que más le tocan a la ciudadana democrática y a la agente económica surgen del ámbito personal. ¿Cómo pueden Habermas y Kohlberg sostener una posición tan contraria a nuestras intuiciones, tan opuesta a la fenomenología de nuestra experiencia moral? Fijémonos con más detenimiento en la argumentación que segrega los temas éticos de la justicia de las cuestiones evaluativas referentes a la vida buena.

b) Mantendría la tesis de que tanto Habermas como Kohlberg confunden el punto de vista de una ética universalista con una definición estrecha del ámbito moral, definición según la cual éste se centraría en "cuestiones de justicia». Pero ambas cuestiones, el universalismo y el ámbito moral, son temas diversos, ya que cómo definamos el ámbito moral es problema distinto del tipo de restricciones en el orden de la justificación a las que consideramos que se ven sometidos los juicios, los principios y las máximas morales. ${ }^{21}$ En una teoría moral el universalismo opera al nivel de especificar qué formas de justificación son aceptables para los principios, los juicios y las máximas morales. "Universalismo» en el ámbito de lo moral quiere decir, en primer lugar, un compromiso con el igual valor y dignidad de todo ser humano en virtud de su humanidad misma; en segundo lugar, la dignidad de la otra persona como individuo moral se reconoce por el respeto que mostramos a sus necesidades, intereses y puntos de vista en nuestras deliberaciones morales concretas. Y ese respeto moral se manifiesta en las deliberaciones morales teniendo en cuenta el punto de vista de la otra, como una otra generalizada y como una otra concreta; en tercer lugar, el universalismo implica un compromiso de aceptar como válidas las normas intersubjetivas y las reglas de acción tal como se generan en los discursos prácticos, discursos cuyas restricciones he analizado en otros lugares. En ética, el procedimiento universalista se limita a determinar un modelo de deliberación individual y colectiva, y a imponer restricciones sobre los tipos de justificación que conducen a determinadas conclusiones, y no opera especificando cuál es el ámbito de lo moral. Quizá un ejemplo nos ayude a aclarar estas cuestiones.

Imaginemos que en una familia de tres hermanos uno de ellos tiene graves compromisos financieros y es incapaz de atender a sus compromisos. El punto de vista del cuidado que tanto Gilligan, Lawrence Blum, como yo misma reconocemos, nos diría que hay aquí prima facie una exigencia moral, a saber, la que interroga si los otros dos miembros de la familia que tenemos más suerte tenemos obligación moral de ayudar a ese hermano. Esa obligación moral nace de la naturaleza especial de las relaciones que tenemos con esa persona concreta. Tal obligación pudiera en- 
tenderse como una obligación de justicia, pero no es necesario que así sea. Si nosotros, los hermanos mayores, hubiéramos llegado en la vida hasta donde lo hicimos apropiándonos de la herencia familiar y dejando al pequeño desheredado, la situación moral que hemos descrito sería también una situación de justicia y referiría a lo que se le debe moralmente al hermano menor. Pero si nuestra posición en la vida no obedece sino a nuestro arduo trabajo y a nuestra buena estrella, las obligaciones que tenemos con respecto a nuestro hermano no emanarían de consideraciones de justicia. Desde un punto de vista kantiano, esta obligación podría comprenderse como de «benevolencia». $Y$, de hecho, se ha dicho que, por lo que a la posición de Gilligan respecta, la ética del cuidado y de la responsabilidad abarcan aquel mismo espectro de cuestiones que Kant calificó como de «deberes positivos» de la benevolencia o del altruismo. Se mantienc, así, que el ámbito de lo ético difiere de lo supererogatorio o del altruismo, aunque ello no obste para que los actos que emanan de estas actitudes pudieran considerarse la corona de un caracter virtuoso. ${ }^{22}$

Me gustaría argumentar, frente a esta consideración de los temas referentes al cuidado como temas supererogatorios o altruistas, y de nuevo con Gilligan y con Blum, y contra Habermas y Kohlberg, que las obligaciones y las relaciones concernientes al cuidado son genuinamente morales, que pertenecen al núcleo de lo moral y que no son marginales con respecto a ese núcleo. Si los miembros de la familia del ejemplo que hemos elegido no ven ni reconocen el carácter moral de su circunstancia, es decir, si no son capaces de entender tal situación como «moralmente relevante», carecerían de sensibilidad moral. Pero, hablando estrictamente, no cabría decir que esa situación, que es moralmente relevante, sea también una situación relevante desde el punto de vista de la justicia. No habría nada «injusto" si los dos hermanos mayores deciden no ayudar al pequeño, pero sus actos mostrarían algo moralmente "encallecido", carente de generosidad y de cuidado. A diferencia de Habermas y Kohlberg, no creo que me encontrara dispuesta a pensar que ese «encallecimiento y carencia de generosidad y de cuidado» es una categoría evaluativa y no moral ni que tales consideraciones pertenecen más a la calidad de nuestras vidas que a los procedimientos generales para la regulación de conflictos e intereses intersubjetivos. Tal análisis efectúa una restricción innecesaria e infundada del ámbito de lo moral y no se sigue de una posición universalista. También en este contexto la posición moral universalista de una mentalidad abierta y amplia nos da un procedimiento para juzgar la validez de nuestros juicios.

Lo que se requiere de nosotras en este caso, a la luz de un compromiso con el universalismo ético, es que actuemos de manera coherente respetando la dignidad y el valor de las personas que están implicadas, y que estemos dispuestas a resolver los temas controvertidos por medio de una 
discusion abierta y sin restricciones en la que participen todas. ¿Qué quiere decir esto en concreto? Los hermanos con fortuna y el hermano menor deberían estar dispuestos a participar en un procedimiento discursivo, en una discusión sobre las necesidades de este último y las responsabilidades y expectativas de los primeros. El respeto por el valor y las necesidades del hermano pequeño, como un otro generalizado y como un otro concreto, no nos exigiría menos que tal discusión. Pero el resultado de la misma no puede venir dictado por el procedimiento discursivo mismo. Es posible ciertamente que todos los implicados comprendieran que la ayuda económica de los hermanos mayores no es en ese momento deseable pues pudiera reforzar esquemas de dependencia, crear resentimientos, etc. También es posible que se acordase que con determinada ayuda en ese momento crucial el hermano menor podría encontrar su camino hacia una vida más autosuficiente. Los procedimientos no determinan los resultados concretos, sino que sólo restringen el tipo de justificaciones que podemos usar en nuestras acciones, juicios y principios. Como he defendido en otros lugares, la ética del discurso es una teoría moral deontológica y universalista en la cual las concepciones de lo justo constriñen lo bueno. Es aquí donde me separo de una perspectiva centrada en el cuidado y me acerco a los universalistas.

He argumentado hasta aquí que debemos diferenciar entre la definición o la determinación del ámbito de lo moral y el nivel de la justificación o la argumentación que viene dado por un compromiso en favor del universalismo. Si el universalismo sc entiende procedimentalmente, como debiera hacerse, tal procedimiento podría emplearse para calibrar la validez de los juicios, los principios y las máximas morales incluso en aquellas situaciones que se refieren, tal como Habermas y Kolhberg las definen, más a las "cuestiones evaluativas de la vida buena" que a las "cuestiones éticas de justicia». Las cuestiones referidas al cuidado son temas morales y también pueden ser tratadas desde un punto de vista universalista. Pero tal universalismo fija las constricciones en cuyo seno ha de operar una ética del cuidado.

c) Si recordamos el esquema de Lawrence Blum que antes discutimos se verá que mi posición podría venir representada por las tesis 4,6 y 7 . Los temas del cuidado son genuinamente morales, pero la perspectiva del cuidado no define una teoría moral de la que cabría extraer una comprensión diferenciada de lo que es el punto de vista ético (tesis 4). Las consideraciones de una moralidad universalista fijan de hecho los límites dentro de los cuales ha de permitirse que operen las preocupaciones derivadas del cuidado y "triunfan" sobre éstas si fuere necesario (tesis 6); por último, las consideraciones acerca del cuidado debieran «validarse o afirmarse desde una perspectiva imparcial" (tesis 7). Regresemos por un momento al ejemplo antes dado para especificar todo ello de manera más clara. Suponga- 
mos que los miembros de nuestra familia forman parte del clan de don Corleone (el Padrino) y pertenecen a la Mafia. La Mafia es una organización basada sobre el cuidado y la mutua responsabilidad entre los miembros del propio clan o familia extensa, pero esta moralidad del cuidado se acompaña por una moralidad de injusticia y desprecio hacia las vidas, la dignidad y la propiedad de quienes no son miembros del grupo. Quienes teorizan la dimensión del cuidado debieran especificar en base a qué criterios cabría considerar como «inmorales», desde su punto de vista, a clanes tales como los de la Mafia. Personalmente opino que en este punto no es posible prescindir del universalismo kantiano. Una moralidad basada sólo sobre el cuidado tiene el riesgo de retrotraer a una posición en la cual es moralmente bueno aquello que es bueno para quienes son iguales a mí, y tal posición no es muy distinta de aquella otra que argumenta que es bueno moralmente aquello que más me satisface.

La tesis 6 rezaba que una moralidad universalista debicra fijar restricciones en el seno de las cuales puedan operar las preocupaciones que se centran en la dimensión del cuidado. En el caso de nuestro ejemplo, ello significaría que los hermanos mayores no podrían aconsejarle al pcqueño, desde un punto de vista ético, que el asesinato de $X$ sería una manera adecuada de poner en orden sus asuntos económicos, como tampoco sería coherente con ese punto de vista ético cualquier otra recomendación que violara la dignidad o el valor de otra persona. Lo que es justo limita qué preceptos pueden considerarse pertenecientes a un comportamiento virtuoso y qué es un buen juicio. No sería moral recomendarle al hermano pequeño, por ejemplo, que se casara con una mujer rica para ordenar su vida financiera pues ello implicaría tratar a esa mujer como un medio y sería incompatible con su dignidad humana.

Tal como recoge la séptima tesis, las consideraciones que atienden al cuidado «deben confirmarse o afirmarse desde una perspectiva imparcial». El principio según el cual «los miembros de una familia debieran mostrarse mutuo apoyo, preocupación y cuidadon es, desde mi punto de vista, un principio justificable para todos, y no sólo para unos pocos, pues si pudiéramos enrolarnos en un discurso práctico en el que se debatiese si sería más aceptable para todos los implicados un mundo en el que las familias no practicasen solidaridad alguna que otro en cuyo seno sucediese todo lo contrario, y las familias fuesen solidarias atendiendo a sus miembros con su apoyo, podríamos todos acordar que esta última alternativa casaría mejor con los intereses de todos los implicados. Así, hay una diferencia importante entre el decir que «los miembros de familias judías, irlandesas o italianas deberían mostrarse mutuo apoyo y preocupación y cuidar unos de otros» y el decir que sea cual sea nuestro trasfondo cultural será siempre preferible un mundo en el que los miembros de las familias, o de las instituciones domésticas semejantes a ellas, muestren apoyo, preocupación 
y cuidado unos por otros, que otro mundo en el que tal no sea el caso. Esta segunda afirmación pretende ser una afirmación moral universalizable, mientras que la primera es sólo una articulación etnocéntrica de una moralidad de grupo que posee un doble filo: la solidaridad del grupo puede conseguirse a costa de la desconsideración y el desprecio morales de otras personas que no son miembros de ese grupo.

Pero imaginemos, no obstante, que una kantiana más estricta nos preguntase qué estatuto tiene eșa afirmación "sería preferible un mundo en el cual...». ¿Es acaso una afirmación utilitarista o consecuencialista? ¿Estaremos aseverando con ella que será mayor la suma total de todas las felicidades y bienestares de ese mundo que la de otro mundo diverso? Es evidente que, a cierto nivel, las consideraciones que acabamos de realizar sobre las farnilias moralmente intactas nacen de una preocupación por el bienestar y la riqueza de la vida humana. Si bien es cierto que a la luz de mi posición me siento metateóricamente comprometida con la idea de que la validez de las normas morales generales viene dada por el solo procedimiento discursivo, sin aditamento alguno de principios de utilidad o de bienestar humano, también lo es que como filósofa inserta en el programa discursivo y como feminista me son tan cercanas las necesidades y el bienestar de la otra concreta como la dignidad y el valor de la otra generalizada.

$Y$, en el mismo sentido, cabe decir que Habermas y Kohlberg han desconsiderado con excesiva facilidad una intuición central que opera en Gilligan y en otras feministas, a saber, la intuición de que antes de ser adultas hemos sido niñas y de que la nutrición, el cuidado de las demás y responsabilidad hacia ellas nos es esencial para que lleguemos a convertirnos en personas moralmente competentes y autosuficientes. En términos ontogenéticos ni la justicia ni el cuidado poseen primacía alguna, pues ambas dimensiones son esenciales para que la niña recién nacida, frágil y dependiente, se desarrolle como una persona autónoma y adulta. Y no sólo vivimos en el "tejido de los asuntos humanos», por decirlo en las palabras de Hannah Arendt, o en redes de "cuidado y dependencia", por hacerlo con las de Gilligan, cuando somos niñas sino que también vivimos así como seres concretos y corporales que tienen necesidades, emociones y deseos, y que son vulnerables. La filosofía moral moderna, y en concreto las teorias universalistas de la justicia, han acentuado nuestro valor como personas morales a costa del olvido y de la represión de nuestra vulnerabilidad y dependencia como seres corporales. Tales redes de dependencia y el tejido de los asuntos humanos en el que nos hallamos inmersas no son sólo como vestidos que se nos van quedando pequeños o como zapatos que vamos desechando, sino que son como lazos que nos vinculan, lazos que modelan nuestras necesidades morales, nuestras identidades y nuestras concepciones de lo que es la vida buena. El yo autónomo no es 
un yo desencarnado, y la filosofía moral universalista debiera reconocer esa honda experiencia de la formación del ser humano a la que se corresponden el cuidado y la justicia. Gilligan formula la interdependencia entre el cuidado y la justicia con las siguientes palabras:

Teóricamente la distinción entre la justicia y el cuidado atraviesa las conocidas divisiones entre el pensar y el sentir, el egoísmo y el altruismo, el razonamiento práctico y teórico. Esa distinción llama nuestra atención hacia el hecho de que todas las relaciones humanas, tanto públicas como privadas, pueden caracterizarse tanto en términos de igualdad como en términos de afecto y cercanfa, y de que tanto la desigualdad como el desafecto y la distancia dan motivos para la inquietud moral. Ya que todas somos vulnerables tanto a la opresión como al abandono, cabe decir que en la expcriencia humana concurren dos visiones morales, una de justicia y otra de cuidado. Estas diferentes inquietudes se captan en las prohibiciones morales de no actuar injustamente con los demás y de no volverle la espalda a alguien que nos necesite. ${ }^{2 s}$

El reto sostenido que plantean los hallazgos de Gilligan a las filosofías morales universalistas es el de cómo sostener la centralidad de la justicia y del cuidado en las vidas de las personas y de cómo ampliar el ámbito de lo moral de forma tal que se incluyan también en él las consideraciones que se derivan de ese cuidado sin que ello implique dejar de lado las constricciones que, en el orden de la justificación, le impone el universalismo a la moral.

Habermas ha reconocido con algún retraso algunos de los problemas que se suscitan en el debate a propósito de Gilligan en un artículo reciente, "Justicia y Solidaridad. Sobre la discusión a propósito del "Estadio 6" ". Al comentar los últimos esfuerzos de Kohlberg por integrar en una visión moral unificada la justicia y la benevolencia, escribe Habermas:

Por ello, el punto de vista que complementa el tratamiento igual de los individuos no es la benevolencia, sino la solidaridad. Este principio tiene sus raíces en la experiencia de que debemos responsabilizarnos unos de otros pues todos debemos interesarnos por igual en la integridad del contexto de nuestra vida compartida. Una concepción deontológica de la justicia requiere como su reverso de la solidaridad [...] Toda moralidad autónoma ha de cumplir a la vez dos tareas: en primer lugar, hace valer la inviolabilidad de los individuos socializados al requerir un tratamiento igual para ellos así como idéntico respeto para la dignidad de cada uno y, en segundo lugar, protege las relaciones intersubjetivas de reconocimiento mutuo al reclamar la solidaridad de los miembros individuales de una comunidad en la que esos individuos han sido socializados. ${ }^{24}$

Las similitudes de estas dos formulaciones que hemos recogido son sorprendentes. Si Gilligan habla de «igualdad y afecto y cercanía" y de la necesidad de "no actuar injustamente hacia los demás» y de no "volverle 
la espalda a alguien que nos necesita", Habermas lo hace de "solidaridad", del interés que cada uno tiene en la protección de las "relaciones intersubjetivas de reconocimiento mutuon. ${ }^{25}$ Ciertamente, también hay diferencias de énfasis, pues mientras para Habermas la justicia se atempera por el "reconocimiento mutuon (Anerkennung) de los individuos del bienestar de los demás, para Gilligan se atempera con el cuidado recíproco y con un reconocimiento de la dependencia y de la vulnerabilidad. No obstante, en ambas formulaciones los ideales de autonomía moral y de justicia se retrotraen a un común origen en unas relaciones humanas frágiles y «adquieren sus proporciones adecuadas». La otra generalizada de la perspectiva de la justicia es también una otra concreta, y podemos reconocer fácilmente esa concreción si recordamos las relaciones humanas de dependencia, del cuidado, del compartir y del establecer reciprocidad con los demás, en las que se socializa toda criatura humana. Si la teoria feminista ha conseguido recordar a las moralidades universalistas de la tradición kantiana que es necesario compensar "la vulnerabilidad de los seres que se convierten en individuos por medio de procesos de socialización de manera tal que nunca pueden afirmar su identidad por sí solos [...]», ${ }^{26}$ es que se ha producido un significativo giro en el seno de esas teorias, un cambio de paradigma que he descrito en otro lugar como el paso de "un universalismo legaliforme y sustitutorio hacia un universalismo interactivow.

\section{El género y la diferencia en el debate sobre Gilligan}

El trabajo de Carol Gilligan desafía a las teorías morales universalistas que se inscriben en la tradición kantiana a que amplien su definición del ámbito moral, les cuestiona sus ideales de un yo autónomo a la luz de las experiencias de las mujeres y los niños y las lleva a reconocer que deben también escuchar la voz de los «otros excluidos», En los últimos años, el debate en torno a la cuestión de las mujeres y la teoría moral ha estado también en el centro de una preocupación general de la teoría feminista respecto al problema de la "diferencia». Algunas de las críticas más fuertes al trabajo de Gilligan han sido las de algunas feministas que la han acusado de hipostasiar ilegítimamente la "voz» de las mujeres blancas, heterosexuales y con una carrera profesional. ${ }^{27}$ Si para las disciplinas académicamente establecidas el hecho mismo de la "diferencia» es un tema subversivo, esa temática es, sobre todo, la preocupación central en toda teoría feminista que intente desentrañar su construcción ideológica y explicar su constitución histónica y social.

¿Es la voz de las mujeres una voz realmente "diferente»? ¿Puede concebirse una "voz de la mujer" independientemente de las diferencias de raza y de clase y puede esa voz abstraerse del contexto sociohistórico? ¿Cuál es el origen de la diferencia del razonamiento moral entre hombres 
y mujeres que Gilligan ha encontrado? ¿Repiten esos análisis, que muestran la tendencia de las mujeres a razonar desde el punto de vista del "cuidado y la responsabilidad", simplemente los estereotipos establecidos a propósito de la femineidad? Para desentrañar los muchos problemas que laten tras esas preguntas, distinguiré a continuación entre los tratamientos metodológicos, reduccionistas y postmodernos de la cuestión de la diferencia de las mujeres en el seno de la teoría moral.

\section{a) Aspectos metodológicos}

En ulteriores reflexiones sobre su trabajo, Gilligan hizo notar que lo había titulado deliberadamente "con una voz diferente" y no "con la voz de las mujeres». ${ }^{28}$ Su objeto de investigación no era la determinación de las "diferencias debidas al sexom en el razonamiento moral, tal como algunos de sus críticos mantenían que había hecho. Más bien, sólo comparó la experiencia de las mujeres con la teoría psicológica - así reza el subtítulo de su libro- para mostrar que la exclusión de las mujeres y de sus experiencias en las principales teorías evolutivas de la psicología generaban modelos $\mathrm{c}$ hipótesis que no eran «universales» ni «neutrales».

La categoría de "género» no guió ni analítica ni metodológicamente los primeros trabajos de Gilligan. Parece que la determinación empírica de diferencias de género precedió en su investigación al uso del género como una categoría explícita de investigación. Por «género» entiendo la construcción diferencial de los seres humanos en tipos femeninos y masculinos. El género es una categoría relacional que busca explicar la construcción de un tipo de diferencia entre los seres humanos. Las teorías feministas, ya sean psicoanalíticas, postmodernas, liberales o críticas coinciden en el supuesto de que la constitución de diferencias de género es un proceso histórico y social, y en que el género no es un hecho natural. Aún más, y aunque exista cierto desacuerdo al respecto, mi posición acordaría con el reciente trabajo de Londa Schiebinger, Judith Butler y Jane Flax ${ }^{29}$ en el sentido de que es necesario cuestionar la oposición misma entre sexo y género. La diferencia sexual no es meramente un hecho anatómico, pues la construcción e interpretación de la diferencia anatómica es ella misma un proceso histórico y social. Que el varón y la hembra de la especie difieren es un hecho, pero es un hecho también siempre construido socialmente. La identidad sexual es un aspecto de la identidad del género. El sexo y el género no se relacionan entre sí como lo hacen la naturaleza y la cultura pues la sexualidad misma es una diferencia construida culturalmente.

Ha sido la ausencia del género como categoría de investigación en el trabajo de Gilligan lo que ha creado algunas de las más serias desconfianzas ante sus resultados. Linda Kerber señala este extremo en sus comentarios titulados "Some Cautionary Words for Historians" ${ }^{30}$ 
In A Different Voice forma parte de una importante redefinición feminista del vocabulario social. Lo que antes se despreciaba como cotilleo puede apreciarse ahora como el mantenimiento de una tradición oral, lo que antes devaluaba como cosa doméstica se entiende ahora como reproducción social y como una contribución crucial al producto nacional bruto. Es revitalizadora la insistencia de Gilligan en que comportamientos antes denigrados por su imprecisión, su confusión y su carácter menospreciablemente «femenino» debieran más bien valorarse por su complejidad y por su capacidad constructiva y humana. Pero, como historiadora, no puedo quitarme de encima la impresion de que ese argumento es ya conocido aunque se nos presente con nuevos ropajes. Algunas de sus variantes son tan viejas como la misma civilización occidental; un aspecto central de la tradición de nuestra cultura ha sido la adscripción de la razón a los hombres y del sentimiento a las mujeres [...] Esa antigua tradición se ha visto reforzada por la socialización explicita que les atribuía a los hombres el poder público mientras que las mujeres quedaban relegadas a las tareas domésticas, socialización que se ha visto a veces defendida con razones basadas en la eficacia y con argumentaciones tomadas de la biología. Aunque Gilligan parece añadir ahora razones tomadas de la psicología, su estudio parece inferir a veces que el comportamiento según el género está determinado biológicamente y otras parece decir que es un comportamiento también aprendido, aunque lo fuera en un momento de la socialización anterior a lo que habían pensado otros investigadores.

Kerber formula adecuadamente su idea. No obstante, es muy poco convincente el creer como ella que Gilligan consideraba los estilos de razonamiento moral que identificó en su estudio y las preferencias de las mujeres por razonar con más frecuencia en un estilo que en otro como si reflejaran una esencia ontológica y universal que llamaríamos «femineidad». En su trabajo, el problema de las diferencias de género es mucho más complicado y descansa, en último término, en la ahistoricidad del enfoque de la psicología evolutiva cognitivista, teoría en cuyo seno comenzó, al menos inicialmente, a plantear su investigación. Ese enfoque, tal como ha sido elaborado por Piaget y Kohlberg, se ocupa de la ontogénesis, es decir, del desarrollo del individuo, y no de la filogénesis, o desarrollo de la especie. Esa teoría construye un modelo para explicar cómo el desarrollo del juicio moral del niño y del adolescente es un proceso de maduración en que juega un papel crucial la interacción entre el medio ambiente y las capacidades que la mente humana tiene para estructurar la experiencia. Esa interacción entre el yo y el mundo tiene ciertos momentos de incongruencia y de crisis en el proceso de crecimiento, crisis que no pueden solventarse en el seno de un esquema de razonamiento anterior y que requieren que el sujeto progrese a estadios «superiores» de razonamiento moral. Kohlberg sostiene que los estadios "superiores» de razonamiento moral no sólo acontecen posteriormente en el tiempo, sino que también son más "adecuados" para la resolución de dilemas morales desde un punto de vista cognitivo y filos6fico. 
El sujeto de quien esta teoría habla es, por definición, neutral respecto al género pues se dice que las capacidades en cuestión son relativas a la especie. Pero, como es evidente, la teoría misma tiene un subtexto que viene marcado por el género. Dado que los aprendizajes morales son el resultado de determinadas clases de actividades, podríamos fácilmente indagar si éstas son las mismas para niños y niñas. ¿Son neutrales con respecto al género los juegos infantiles? Recordemos el comentario de Piaget en el sentido de que en el juego de las canicas los niños varones muestran un grado de precisión y de atención compleja a las normas del juego, así como una tendencia a negociaciones basadas en esas normas, que parecen estar ausentes de los juegos de las niñas. ${ }^{31} \mathrm{Y}$, lo que es más, dado que esta teoría sostiene que el desarrollo de estadios "superiores" de razonamiento moral está ligado a las oportunidades que el sujeto tiene para asumir diferentes roles en la vida social, podríamos fácilmente suponer también que serán diversos los roles que asumirán las mujeres y los hombres en un mundo marcado por diferencias de género.

Carol Gilligan rechazó a otro nivel distinto la neutralidad con respecto al género que caracteriza el modelo de Kohlberg. En vez de centrarse sobre ese subtexto de actividades y roles sociales referidos al género, se fijó sobre los esquemas de personalidad de los sujetos. Gilligan se apoyó sobre el trabajo de Chodorow, The Reproduction of Mothering. Por decirlo brevemente, lo que Chodorow mantiene es que los procesos de separacion e individuación por los que ha de pasar toda criatura humana se desarrollan de forma diversa según se sea varón o hembra. En el caso del niño varón, la separación y la individuación implican el establecimiento de una identidad de género que es la opuesta a la figura nutricia primaria, la mujer, aunque no necesariamente a la madre biológica. Convertirse en niño implica no sólo llegar a ser algo separado o distinto de mamá, sino algo diferente; implica, por lo tanto, la represión de aquellos rasgos de la personalidad que más claramente se identifican con la madre. Para las niñas, por el contrario, llegar a ser una niña consiste en convertirse en algo distinto de mamá, pero también igual a ella. La identidad de género está ya establecida a los dos años y medio o tres. En una sociedad patriarcal, basada sobre la denigración y la opresión de las mujeres, la identidad de género está directamente asociada con la internalización de aquellas actitudes que también devalúan y denigran a las mujeres.

Gilligan y Chodorow están de acuerdo en que este desarrollo psicosocial de la niña y del niño pequeños arroja como consccuencia determinados esquemas de personalidad entre los adultos de la especie. El varón tiene un sentido de los límites del yo más firmemente establecido según el cual la distinción entre el yo y el otro es más rígida. Las mujeres, por el contrario, están más predispuestas a mostrar sentimientos de empatía y simpatía con respecto a los demás pues las fronteras entre su yo y los 
otros son más fluidas. Cada uno de estos esquemas de personalidad conlleva también determinadas deformaciones. Mientras los varones experimentan las cercanías y los vínculos como amenazas a su persona, a las mujeres les cuesta más el establecimiento de un claro sentido de la identidad y de la individualidad en tanto distinto y aun enfrentado a las demandas de otros.

Este modelo psicosexual, tal como ya sabemos, no es una teoría que sea capaz de explicar la emergencia de la diferenciación de los géneros, sino que simplemente nos suministra un esquema que da cuenta de su «reproduccion»». Según este modelo, la figura maternal será siempre una mujer, pues el padre estará ausente durante los tres primeros años de la vida de la criatura recién nacida. También se da por supuesto que la actividad materna está socialmente denigrada por el contexto social extenso de manera que el niño varón aprende pronto a asociar esa actividad con características y valores negativos o, por lo menos, ampliamente ambivalentes. El modelo de Chodorow supone la diferencia de géneros en su forma característicamente moderna, pero no explica su constitución histórica y social. El modelo supone la denigración patriarcal de los atributos del género femenino y explica su reproducción, pero no su origen histónico. $Y$, en la medida en que Gilligan se apoyó sobre este modelo, dejó también sin explicar la construcción social del género: por un lado, señaló la desconsideración de esa cuestión por parte de la teorfa psicológica hegemónica y, por otro, llamó la atención sobre su persistencia como un subtexto continuo pero inexplicado en el seno de esas teorías.

Linda Kerber acierta al señalar que las diferencias de género quedan sin explicar en el trabajo de Gilligan. Para el desarrollo de esa tarea tenemos que dejar la teoría moral y adoptar una teoría social de las relaciones de los géneros; hemos también de abandonar la teoría psicológica y acogernos a los estudios de la sociología histórica sobre el desarrollo y la constitución del género. El género como categoría analítica subvierte, por lo tanto, las fronteras establecidas entre las disciplinas.

\section{b) Objeciones reduccionistas}

Si las feministas y las historiadoras de la mujer, como Linda Kerber, criticaron metodológicamente a Carol Gilligan por el olvido de la historicidad en los resultados de su trabajo y por ignorar los determinantes históricos de las diferencias de las mujeres que ella habia hallado en la teoría moral, otras investigadoras argumentaron que el tipo de "diferencia» que Gilligan había hallado y que había calificado de femenina era una diferencia opresora. Claudia Card y Catharine MacKinnon han puesto voz a la sospecha de que la moralidad del «cuidado y la responsabilidadn es una versión de la moralidad de los esclavos que Nietzsche retrata. ${ }^{32}$ Card escribe que «los 
estudios sobre los valores de la mujer podrían sacar ventajas de Nietzsche, cuyas obras sobre ética se refieren directamente a las consecuencias de la dominación y la subordinación sobre el desarrollo del carácter y los ideales. Aunque su objetivo era la ética cristiana, sus ideas podrian aplicarse a los valores de las mujeres que han sido recientemente señaladosm. ${ }^{33} \mathrm{Si}$ guiendo a Nietzsche, Card aboga por que se considere el «envés de la ética de las mujeres" ${ }^{34}$ Para Nietzsche, la moralidad es una sublimación del impulso vital de los fuertes hacia el dominio de los débiles, y los orígenes de la moralidad han de hallarse en los controles intemalizados que se le imponen a aquellos por parte de éstos de manera que los débiles no resulten dañados.

MacKinnon, por su parte, no vuelve a Nietzsche sino a la teoría marxista de la lucha de clases. De la misma manera que las «ideas dominantes" son las ideas de las "clases dominantes», así también las concepciones morales dominantes son el resultado de un sistema de opresión genérico y de clase en la forma de una heterosexualidad obligatoria. De acuerdo con Mackinnon, poco más ha hecho Gilligan que elevar a categoría científica la imagen de "niña buena» que tiene de las mujeres la cultura heterosexual y cuyo propósito es "domesticar" a las mujeres retratándolas como seres "cariñosos, dados al cuidado y la responsabilidad". Escribe MacKinnon: "Por otra parte, lo que es más irritante (lo cual es algo grave de decir de un libro [In A Different Voice, S.B.] tan sereno, grácil y amable en su emocionalidad), y es una irritación política, es que olvida el nivel de la explicación. Ella [Gilligan] ha encontrado también la voz de la víctima: sí, las mujeres son también un grupo victimizado. La articulación de la voz de la víctima es crucial porque las leyes contra la victimización están normalmente hechas por personas que tienen poder y vienen desde la perspectiva del poder [...] Pero me inquieta la posibilidad de que las mujeres se identifiquen con lo que es un estereotipo femenino valorado positivamente. Es lo "femenino".$^{35}$

Estas apropiaciones feministas de análisis nietzscheanos y marxistas reducen los problemas normativos de la justicia y la moralidad en sociedades complejas a meros esquemas de camuflaje del interés o del poder. Ambas concepciones son hondamente antipolíticas: para Nietzsche la perspectiva última es la de una utopía estética de la sabiduría en la que un sabio viejo, Zarathustra, alcanza un estado de autonomía más allá de la comunidad. Y si en vez de repetir ciegamente a los pensadores del pasado aplicásemos la metodología feminista a la utopía moral última de Nietzsche, volveriamos a descubrir en ella otra versión del yo autónomo masculino. Ese ideal no se presentará, ciertamente, como el severo legislador kantiano, sino como el héroe artístico, poético, 'multifacético pero irrenunciablemente masculino: Zarathustra, que es a la vez «cordero y león». ${ }^{36}$ Este ideal arcaico del héroe masculino que es bello y sabio es dudosamen- 
te un objetivo en el que debiera concluir el debate contemporáneo sobre las mujeres y la teoría moral.

El tratamiento reduccionista con el que Nietzsche analiza lo moral en sus primeros escritos se empareja en los últimos con la utopía estética de un varón sabio que vive "más allá del bien y del mal". Por su parte, la teoria reduccionista marxista de la moralidad, que la concibe como una mera expresión de los intereses de las clases dominantes es inseparable de la utopía de una sociedad de total reconciliación. De la misma manera en que todos los conflictos interpersonales y todos los conflictos debidos a recursos escasos llegarán a su fin cuando se eliminen los conflictos de clase, así también cesará de existir toda "diferencia de género" con el final del actual régimen de géneros o, por decirlo en la terminología de MacKinnon, con el final del régimen de "heterosexualidad obligatoria». ${ }^{37} \mathrm{El}$ "gobierno de los hombres sobre las mujeres» será sustituido por «la administración de las cosas». En el caso de Mackinnon, la utopía no es, pues, la de un bello varón arcaico sino la imagen de una sociedad de poder perfecto y autotransparente, regida de forma totalmente racional. $\mathrm{Si}$, por otra parte, aceptamos que ni los conflictos interpersonales, ni la escasez económica, ni las causas de la vulnerabilidad y la necesidad humanas son fácilmente eliminables, incluso en una sociedad más justa, la teoría moral no puede desecharse como si sólo representara las ideas dominantes de los varones heterosexuales. Siempre será necesario regular las causas del conflicto y de las disputas humanas y proteger los compromisos de una existencia humana compartida. Una afirmación como la que a continuación recojo, y que procede por medio de una serie de oposiciones dogmáticas, como las de moralidad y política o liberalismo y radicalismo, indica con claridad que la comprensión que MacKinnon tiene de la política y de la moralidad tiene más puntos en común con las utopías autoritarias del leninismo que con la tradición de la teoría crítica marxista: "En mi opinión -escribe-, asumir la perspectiva de la diferencia es adoptar una perspectiva moral, mientras que criticar la jerarquía es adoptar una perspectiva política. Adoptar una perspectiva de la diferencia es también asumir una perspectiva liberal (aunque, por supuesto, aquella implique también conservadurismo) mientras que adoptar la perspectiva que defiendo contra la jerarquía es asumir una perspectiva radical. También creo que hacer pivotar las cuestiones del género sobre la así llamada diferencia de géneros es, en último término, adoptar una perspectiva masculina. Por eso, denomino masculinista a la perspectiva de la diferencia. Por el contrario, aquella posición que defiende que el género es ante todo un jerarquía política de poder es, en mi opinión, una posición feminista». ${ }^{38} \mathrm{La}$ otra cara de la negación de la política es una política autoritaria que pondrá fin a toda diferencia, a toda controversia, a todo conflicto y a toda violencia entre los seres humanos. 39 


\section{c) Reservas postmodernas}

Si Claudia Card y Catharine MacKinnon prescindirían del ideal de autonomía, y quizá también totalmente de la dimensión moral, las feministas postmodernas, por el contrario, se esfuerzan por desarrollar un concepto "descentrado" y "fracturado" del yo con el que sustituir la idea del yo cen conexión" o "relacional», noción que consideran privilegiada en el trabajo de Gilligan.

Jane Flax e Iris Young se han inspirado en las críticas postmodernas al «yo de la identidad» y han criticado el yo «relacional». Argumentan que la tradición filosófica occidental ha privilegiado la identidad sobre la diferencia, la unidad sobre la multiplicidad, la permanencia sobre el cambio. El sujeto del discurso filosófico occidental se constituye a costa de la supresión de la diferencia, de la exclusión de la otredad y de la denigración de la heterogeneidad. Desde Platón hasta Kant, pasando por Descartes, el yo es un sustrato unitario e idéntico, las pasiones se rinden a la razón, el yo reina sobre la voluntad, y la otredad ha de ser suprimida.

Young considera que si comprendemos al yo en esos términos empáticos y relacionales, damos por supuesto un estado ken el cual las personas dejarán de ser opacas, otras, incomprendidas, y se tornarán en seres mutuamente simpatéticos y tan comprensivos los unos de los otros como de sí mismos. Tal ideal de subjetividad compartida, o de transparencia de los sujetos unos con otros, niega la diferencia en el sentido de una asimetría básica entre los sujetos». ${ }^{40}$ No sólo se da por supuesta esa transparencia intersubjetiva, sino que también es cuestionable la ficción de la subjetividad como el centro unificado del deseo: pero, «como el sujeto no es una unidad, no puede estar presente ante sí mismo, conocerse a sí mismo [...] No siempre sé lo que quiero decir, lo que necesito o deseo, porque todo ello no arranca de un origen en el yo [...] Consiguientemente, todo individuo es un juego de diferencias que no puede comprehenderse [...] el sujeto es [una] presencia heterogénean. ${ }^{41}$ Young concluye que el concepto cartesiano-kantiano de la unidad del yo, al igual que le sucede a la teoria feminista del yo relacional, perpetran una "metafísica de la presencia" y una "lógica de la identidad".

Young piensa, así, que la concepción que Gilligan tiene del yo no pone en cuestión las concepciones tradicionales de la autonomía y de la identidad que se han forjado en el pensamiento filosófico occidental, sino que suscribe sus supuestos fundamentales al dar por sentado que los sujetos pueden verdaderamente comprenderse los unos a los otros y que el individuo es un sujeto coherente de deseos. Pero la afirmación de Young de que el cuidado y la responsabilidad mutuas suponen una "transparencia» de la comprensión de los sujetos es una afirmación exagerada. Una comprensión o fusión tal de mentes sería, quizá, una crítica ajustada a la concep- 
ción kantiana de los yoes nouménicos, pero ni en la idea del "otro concreto" que yo he desarrollado, idea que Young también critica, ni en la de Arendt de una "mentalidad abierta y amplia" se supone en absoluto que haya un estado de comprensión perfecta. Young no presta atención a la diferencia entre "consenso" y "alcanzar un entendimiento" que he introducido en otros lugares al analizar la ética del discurso habermasiana. Ciertamente las teorías racionalistas ilustradas, y en concreto la teoría rousseauniana de la democracia, se basaban en la ilusión de que era posible un consenso perfecto, pero el modelo de ética dialógica que he defendido en mis últimos trabajos se refiere, más bien, a un proceso de conversación continua en el que siempre se entrelazan y están presentes la comprensión y las incomprensiones, el acuerdo y el desacuerdo. Incluso la idea misma de conversación como medio para alcanzar una mentalidad abierta y amplia deja ver la infinita revisabilidad e indeterminación del significado.

Y la crítica de Young, en el sentido de que es una ficción ese yo como centro unificador del deseo, es de nuevo una exageración. Young parece celebrar la heterogeneidad, la opacidad y la diferencia a costa de minusvalorar la importancia que tiene un núcleo coherente en la identidad individual. No toda diferencia es potenciadora ni toda heterogeneidad es de celebrar, no toda opacidad produce un sentido de autoflorecimiento. No nos vemos forzadas a pensar la idea de "identidades coherentes" sobre el modelo de identidad de los objetos físicos y cabe concebir esa coherencia en términos de una unidad narrativa. Lo que unifica un relato puede ser el punto de vista de la narradora, de la que lo escucha o alguna interacción entre el significado que se transmite y el que se recibe. Lo mismo le sucede a la identidad personal. Tal como Hannah Arendt ha acentuado, desde que nacemos nos vemos inmersas en un "tejido de narraciones" del que somos tanto autoras como productos. El yo es tanto la narradora de los relatos como aquello sobre lo que tratan esos relatos. El individuo que tiene un sentido coherente de autoidentidad es aquella que alcanza a integrar estos relatos y perspectivas en una historia de vida con sentido. Cuando el relato de una vida sólo puede narrarse desde la perspectiva de las otras, el yo es una victima sufriente que ha perdido el control sobre su propia existencia. Cuando esa historia sólo puede relatarse desde el punto de vista del individuo, ese yo es narcisista y solitario y puede haber alcanzado su autonomía a costa de la solidaridad. Alcanzamos un sentido coherente de la propia identidad cuando integramos con éxito autonomía y solidaridad, cuando mezclamos adecuadamente justicia y cuidado. La justicia y la autonomía solas no pueden sostener ni alimentar ese tejido narrativo en el que se desenvuelve el sentido de identidad de los seres humanos; pero tampoco la sola solidaridad y el solo cuidado pueden elevar al sujeto a ser no sólo el objeto cuanto la autora de un relato coherente de la propia vida. 
Con estas consideraciones llegamos a ciertos temas centrales del núcleo normativo del feminismo contemporáneo, a saber, si el feminismo debe implicarse en una reconstrucción o, por el contrario, en una desconstrucción de la tradición filosófica occidental. ¿Qué le prometen el postmodernismo y la desconstrucción al feminismo? ¿Han de ser aliados? ¿Qué rasgos comunes hay entre ellos y cuáles son las diferencias? Dejo para otro momento el tratamiento de las alianzas contemporáneas entre las actitudes postmodernas y las feministas.

\section{NOTAS}

1. Joan Kelly Gadol: "The Social Relations of the Sexes. Methodological Implications of Women's Historyn, en Women, History and Theory. Chicago, The University of Chicago Press, 1984, pp. 1-14; aqui, pp. 2-3.

2. Alasdair MacIntyre: After Viriue, pp. 44 ss. (Trad. cast. de A. Valcárcel: Tras la viriud, Barcelona, Crítica, 1988.)

3. Michael Sandel: "The Procedural Republic and the Unencumbered Selfw, political Theory, 12, 1 (1984).

4. Gilligan ha guardado un sorprendente silencio respecto al problema del relativismo étrico y cultural del paradigna de Kohlberg.

5. Taylor: "Die Motive einer Verfahrensethik», en W. Kuhlmann (ed.), Moralität und Sittlichkeit, Francfort, Suhrkamp, 1986; Michael Walzer: Interpretation and Social Criticism. Cambridge, Mass., Harvard University Press, 1987.

6. Hemos analizado los puntos en común y las tensiones que existen entre estas dos aproximaciones en la Introducción a Seyla Benhabib y Drucilla Comell (eds.), Teoria feminista y Teoria critica, Valencia, Alfons el Magnànim, L'IVEI, 1990.

7. Owen Flanagan y Kathryn Jackson dan un aclarador panorama de los problemas implícitos a las diversas formulaciones de Gilligan hasta la fecha respecto a ambas perspectivas. Escriben: «[...] su trabajo reciente todavia oscila entre la idea de que ambas éticas son altemativas incompatibles entre si, pero que ambas son adecuadas desde un punto de vista normativo, de que se complementan entre sí en una suerte de tenso juego mutuo y de que cada una de ellas es deficiente sin la otra y que debe integrarlam. Cf. *Justice, Care and Gender. The Kohlberg-Gilligan Debate Revisited», Ethics, 97 (abril, 1987), pp. 622-637; aqui, p. 628.

8. Cf. Nel Noddings: Caring. A Feminine Approach to Ethics and Moral Education, Berkeley. University of California Press, 1984. El razonamiento dicotómico de Noddings, que diferencia tajantemente entre ala ley y la justicia» como masculinas, y la ureceptividad, la relación y la respuesta» como femeninas, se encuentra enfrentado con la perspectiva de Gilligan y con mi intento de superar estas fuertes dicotomías en un acercamiento más integrador al razonamiento y el juicio morales. Véanse las páginas 2 ss. de su obra para una formulación especialmente tajante.

9. Lawrence A. Blum: "Gilligan and Kohlberg: Implications for Moral Theory", Ethics, 98 (abril, 1988), pp. 472-491; aquí, p. 472.

10. Ibid, p. 477 .

11. El mismo Kohlberg ha suscrito, en diferentes momentos del debate, alguna versión de la mayoría de las posturas que esta enumeración recoge. He señalado en otros lugares algunas de las ambigizedades de sus respuestas a Gilligan.

12. Blum: "Gilligan and Kohlberg", art, cit., p. 478.

13. Ibid, p. 479 .

14. Ibid, p. 481.

15. Ibid., p. 482. Blum se refiere aquí a la postura de Kohlberg en uSynopses and Detai- 
led Response to Critics", en The Psychology of Moral Development, San Francisco, Harper and Row, 1984, p. 343.

16. J. Habermas: Morabewusstsein und kommunikatives Handein, Francfort, Suhrkamp, 1983, pp. 189 s.

17. lbid., p. 191.

18. Ibid.

19. Ibid., p. 193.

20. Kohlberg: "Synopses and Detailed Response to Critics», art. cit., pp. 229-230.

21. Hay un leve reconocimiento de esta idea en el artículo de Habermas, "Gerechtigkeit und Solidarität. Zur Diskussion uber "Stufe 6" ${ }^{\prime}$, en Exläuterungen zur Diskursethik, Francfort, Suhrkamp, 1991, pp. 49-76, cuando señala en la p. 65: "Pero las justificaciones étjoo-procedimentales se aplican también a los principios de la justicia distributiva [...] o los principios del cuidado y de la ayuda a los que están necesitados de ellos, a las convenciones de la autoconstricción, de la consideración, de la veracidad, al deber de ilustrar a otros, etc.s. No obstante, esta idea queda sin desarrollar y su importancia permanece difusa dado que si la ética procedimental puede aplicarse tanto a ternas de justicia distributiva como a los principios del cuidado y a diversas virtudes referidas al sujeto, entonces el ámbito de lo moral no sólo comprende temas de justicia, sino que también abarca cuestiones evaluativas que competen también a la vida buena. ¿O querrá Habermas decir que la ética procedimental se puede aplicar a fenómenos como «la consideración y la veracidad" en la medida, y sólo en ella, en que esos fenómenos se pueden reconceptualizar como cuestiones de justicia? Si no es difícil imaginar cómo el cuidado y la ayuda a los demás, así como la veracidad, pueden ser tanto fenómenos morales de justicia como cuestiones referidas a la vida buena del individuo y de la colectividad, es más difícil imaginar cómo la "consideración" y la uautoconstricción" pueden clasificarse como fenómenos de justicia. Habermas no puede jugar a dos bandas: por una parte insiste en que hay una clara distinción entre las cuestiones de justicia y las de la buena vida, y sostiene que la ética discursiva se refiere sólo a las primeras; pero, por la otra, quiere definir el principio discursivo de manera que no defina el ámbito de lo moral sino como si sólo especificase niveles y formas de la argumentación moral justificable. Tal como argumento en el presente trabajo, es esta úlírna consideración la que debe defenderse, mientras que la primera debe ser abandonada. El tema a discutir no es la definición del ámbito de lo moral, el qué preguntas son o no morales; obviamente, tanto las cuestiones de justicia como las de la vida buena son temas morales. Más bien, el problema es cómo circunscribir el ámbito de la autonomía individual (tanto legal como políticamente) en el que se ejercitan las elecciones que competen a formas diversas de la vida buena de manera tal que sea compatible con los principios universalistas de justicia.

22. Cf. G. Nunner-Winkler: «Two Moralities? A Critical Discussion of an Ethik of Care and Responsibility versus an Ethik of Rights and Justice», en W.M. Kurtines and J.L. Gewirtz (eds.), Morality, Moral Behavior, and Moral Development, Nueva York, Wiley, 1984, pp. 348361.

23. Carol Gilligan: «Moral Orientation and Moral Development» en E.F. Kittay y Diane T. Meyers (eds.), Women and Moral Theory, Nueva Jersey, Rowmand and Littlefield, 1987, p. 20.

24. Habermas, "Gerechtigkeit und Solidarität», art. cit., p. 70.

25. El tema del "reconocimiento mutuon y el significado de estas relaciones de reconocimiento en la teoria moral fueron el centro del Habilitationsschrift de Axel Honneth: Kampf und Anerkennung. Ein Theorieprogramm in Anschluss an Hegel un Mead, Francfort. [Puede verse en castellano: «Integridad y desprecio. Motivos básicos de una concepción de la moral desde la teoria del reconocimienton, Isegoria, 5 (1992), pp. $78-92(N$, del $T$.).]

26. Habermas: "Gerechtigkeit und Solidarität", art. cit., p. 69.

27. Cf, para una formulación temprana de esta crítica, Linda Nicholson: «Woman, Morality and History", Social Research, 50, 3 (otoño, 1983), pp. 514-537.

28. Carol Gilligan, Ellen C. Dubois, Mary C. Dunlop, Catharine A. MacKinnon y Carrie J. Menkel-Neadow: "Feminist Discourse, Moral Values and the Law. A Conversation», The 1984 
James McCormick Mitchell Lecture, Buffalo Law Review, 34, 1 (inviemo, 1985), pp. 11-87; aquí, p. 39.

29. Cf. Londa Schiebinger: "Skeletons in the Closet. The First Illustrations of the Female Skeleton in Eighteenth-Century Anatomy", en Catharine Gallagher y Thomas Laquer (eds.), The Making of the Modem Body. Sexuality and Society in the Nineteenth Century, Berkeley, University of California Press, pp. 42-83; Judith Butler: "Variations on Sex and Gender. De Beauvoir, Wittig and Foucault», en S. Benhabib y D. Cornell: Teoría feminisia y Teoría critica, op. cit; Jane Flax: "Postmodernism and Gender Relations in Feminist Theory", Signs, 12, 4 (1987), pp. 621-643. He discutido en otros lugares mis desacuerdos con Butler y Fax.

30. L. Kcrber, «Some Cautionary Word for Historians», en «On In a Different Voice. An Interdisciplinary Forum*, Signs, 11, 2 (invierno, 1986), pp. 304-310; aquí, p. 306. Cf. también Linda Nicholson: "Women, Morality and History" en women and Morality", número especial, Social Research, 50, 3 (otoño, 1983), pp. 514-537, para reparos similares respecto al trabajo de Gilligan.

31. Jean Piaget: The Moral Itudgment of the Child (trad. de Marjorie Gabain), Nueva York, Free Press, 1965, p. 77. (Trad. cast.: El criterio moral en el niño, Barcelona, Martínez Roca, 1984.)

32. Cf. Claudia Card, "Women's Voices and Ethical Ideals: Must We Mean What We Say?, Ethics, 99, 1 (cotubre, 1988), pp. 125-136. Hay que valorar positivamente la preocupación de Card por la forma en que una ética del cuidado pueda esconder o silenciar los sentimientos de agresión o de manipulación que puedan sentir aquéllos a quienes se dirige tal cuidado y atención, así como el que una ética del cuidado en exceso sacrificial pudiera ser profundamente distorsionadora de la personalidad. No obstante, Card es injusta con respecto a Gilligan al señalar que ésta idealiza «la aproximación que se fija en el cuidado», pues la misma Gilligan llama la atención en diversos momentos sobre los peligros de la autoevanescencia y de la autonegación a los que son especialmente propensas las mujeres. Cf. In $\mathrm{A}$ Different Voice, pp. 64 ss. y 123 ss. Cf. también Catharine MacKinnon et al.: «Feminist Discourse, Moral Values and the Law. A Conversation", Buffolo Law Review, pp. 25 ss.

33. Card: "Women's Voices", art. cit., p. 135.

34. F. Nietzsche: La genealogía de la moral, Madrid, Alianza, 1972. Es sorprendente que las ferninistas no ejerzan mayor cuidado a la hora de apropiarse de las categorias nietzscheanas, dado que el empleo de categorias "naturalistas" de diferenciación, como la que se da entre "débiles» $y$ ufuertes", por parte de ese autor, por no mencionar su profundo disgusto hacia las mujeres, es bastante incompatible con la premisa fundamental de la teorización feminista, a saber, que la «diferencia - no sólo entre hombres y mujeres, sino también entre «débiles» $\mathrm{y}$ «fuertes», entre «judíos» y uarios"- no es natural, sino una construcción sociocultural.

35. Mackinnon et al.: «Feminist Discourse, Moral Values and the Law», art. cit. pp. $73-74$.

36. Mark Warren emplea el epiteto adecuado de "conservadurismo neoaristocráticon para caracterizar la ideologia política de Nietzsche, pero diferencia también entre sus intuiciones respecto a las relaciones de poder y sus ideas políticas; cf. su Nietzsche and Political Thought, Cambridge, Mass., MIT Press, 1988, p. 3. A pesar de un tratamiento tan elegante y convincente como el de Warren, permanezco escéptica acerca de la relevancia de Nietzsche para la teoria feminista y creo que la apropiación de su pensamiento por parte de algunas ferninistas, como he discutido a propósito de Judith Butler en otro lugar, causa más problemas que los que aclara.

37. Vẻase su afimación: "La dominación y la sumisión convertidas en sexo, convertidas en la diferencia de génenos, constituyen el contenido social suprimido de las definiciones de género de hombre y mujer", en MacKinnon et al: "Feminist Discourse, Moral Values and the Law", art. cit., p. 27.

38. "Feminist Discourse, Moral Values and the Law", art. cit., pp. 21-22.

39. Puede verse, para un análisis sobre las concepciones, a veces contradictorias, de lo 
político en Marx y en la tradicion marxista, Jean Cohen: Class and Civil Society. The Limits of Marxian Critical Theory, Amherst, The University of Massachusetts Press, 1982; Dick Howard: The Marxian Legacy, Minneapolis, University of Minnesota Press, 1988; y S. Benhabib: Critique, Nom and Utopia. A Study of the Foundations of Critical Theory, Nueva York, Columbia University Press, 1986, parte primera.

40. Iris Young: "The Ideal of Community and the Politics of Differencen, Social Theory and Practice, 12, 1 (primavera, 1986), p. 10.

41. Ibid., p. 11 . 